\section{Symposium on Retinal Diseases}

New Orleans, 6 to ro March 1976

The New Orleans Academy of Ophthalmology 25th Anniversary Symposium on Retinal Diseases, presenting recent advances in diagnosis and management of vitreous surgery, diabetic retinopathy, and macular diseases, will be held in the Marriott Hotel, New

\section{Irish Ophthalmological Society}

\section{Dublin, 29 to 30 April 1976}

The Irish Ophthalmological Society will hold its annual meeting in Dublin. The Montgomery Lecture will be
Orleans. For further information write to Bonnie Crone, Executive Secretary, New Orleans Academy of o Ophthalmology, 515, Audubon Building, 931, Canal $\vec{\circ}$ Street, New Orleans, LA 701 12, USA.

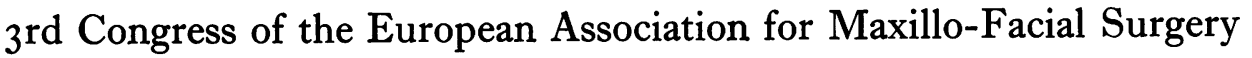

\section{London, 6 to II September 1976}

The 3rd Congress of the European Association for Maxillo-Facial Surgery will be held at the Royal College of Surgeons of England, London. All topics relating to the field of Maxillo-Facial surgery will be delivered in Trinity College on the afternoon of 29 April $ᄋ$ by Professor H. Harms of Tübingen.

\section{International Symposium on Computer Assisted Tomography \\ Bethesda, 12 to 15 October 1976}

An international symposium on computer assisted tomography in non-tumoural diseases of the brain, spinal cord and eye, sponsored by the National Institute of Neurological and Communicative Disorders and Stroke, will be held at the Clinical Center on the campus of the National Institutes of Health, Bethesda, Maryland, covered. Application forms are obtainable from: హี Congress Secretariat, 3 rd Congress EAMFS, $100^{\circ}$ Park Road, London NWI 4 RN.

\section{International Council of Ophthalmology}

\section{Tokyo, I4 to 21 May 1978}

The main themes will be the pigmentary epithelium (including clinical and biochemical aspects and electron under the chairmanship of Giovanni Di Chiro, MD.

Those interested are invited to submit detailed and documented abstracts (data, illustrations) by I August $\frac{\partial}{\partial}$ 1976, to Giovanni Di Chiro, MD, National InstitutesO of Health, Section on Neuroradiology, Clinical Center, Room 2Dr3, Bethesda, Maryland 20014, USA.

\section{Obituary}

\section{B. M. Chatterjee}

Professor B. M. Chatterjee died on 8 June 1975. A graduate from Calcutta Medical College in 1938 he became a Fellow of the Royal College of Surgeons of Edinburgh and England in 1953. He retired from the West Bengal Government Health Service as Professor microscopy), and ocular immunology.

of Ophthalmology in 1971 and became an Emeritus $\stackrel{\mathbb{D}}{\circ}$ Professor at the NRS Medical College, Calcutta In 1972 he was made a Fellow of the American College? of Surgeons. 